Lexis Vol. XLV (2) 2021: 797-824

\title{
El lamento de Houellebecq Una lectura de Las partículas elementales a partir de la noción de masculinidad en crisis
}

\author{
Julián Chaves González \\ https://orcid.org/0000-0002-1211-7906 \\ Universidad Complutense de Madrid \\ juchaves@ucm.es
}

\section{RESUMEN}

El presente artículo propone una interpretación con perspectiva de género de la novela de Michel Houellebecq, Las partículas elementales, centrándose especialmente en la noción de masculinidad en crisis. Para ello, se someten a crítica las premisas con que el autor desarrolla su tesis sobre la liberación sexual y se muestran las implicaciones identitarias con que están construidos sus personajes como hombres en crisis. Asimismo, el artículo se pregunta por el lugar que ocupa la violencia en la obra de Houellebecq y en qué sentido es provocador.

Palabras clave: Houellebecq, masculinidad, género, sexualidad

Houellebecq's Complaint. A Reading of The Elementary particles from the Notion of Masculinity in Crisis

\section{Abstract}

This article proposes an interpretation of Michel Houellebecq's novel The Elementary Particles from a gender perspective, focusing especially on the 
notion of masculinity in crisis. To this end, we criticize the premises with which the author develops his thesis on sexual liberation and we show and revise the identity implications with which his characters are constructed as men in crisis. Likewise, the article questions the place that violence occupies in Houellebecq's work and in what sense it is provocative.

Keywords: Houellebecq, masculinity, gender, sexuality

\section{INTRODUCCIÓN}

Es ya casi un tópico decir que la masculinidad tradicional o hegemónica está «en crisis», identidad a la que, igual que a la modernidad misma, se le estarían comenzando a resquebrajar las creencias - los metarrelatos sobre sí- que la habían, hasta ahora, sostenido. No está muy claro, sin embargo, cuáles son los síntomas de esa crisis, y el diagnóstico suele tener dos lecturas, una optimista y otra pesimista: la primera es la que asegura que los hombres constituyen el primer grupo opresor de la historia que está dispuesto a colaborar con el oprimido, lo que, a raíz del feminismo, habría provocado que aquellos comenzaran a reelaborar su masculinidad en virtud de rasgos que, tradicionalmente, esta había rechazado; la segunda lectura, sin embargo, alude a la reacción conservadora de hombres que ven en el feminismo y en movimientos sociales afines a él, así como en las políticas que de estos se derivan, la causa de sus males, tanto en el amor, como en la sexualidad o en la estima social. Este segundo caso es el que aquí nos interesa.

Michel Houellebecq es un novelista francés, ya célebre, aunque no por todos celebrado, cuya obra podría - y digo podría porque, como veremos, admite muchos matices - darnos la imagen del hombre que sufre la crisis de su masculinidad en ese segundo sentido. Reconstruir la identidad de ese hombre reaccionario - no tiene otro nombre, pues reacciona a los cambios sociales y políticos de su alrededor- es lo que pretende este artículo, para lo que nos centraremos, por cuestiones de espacio, en la novela Las partículas elementales, publicada en 1998 por Flammarion. Esta novela narra 
la historia de Bruno y Michel, dos hermanastros, ambos de mediana edad - crucial en Houellebecq, donde el deseo se desvanece con la vejez-, que, abandonados por una madre cuya decisiva peculiaridad - y la señalo porque importará después - es haber concebido a aquellos en el ambiente hippy y de liberación sexual de los sesenta, conforman dos modelos típicos y antitéticos de hombre: el primero es un obseso sexual que, tras una juventud en que sufrió acoso de todo tipo y con una vida laboral que no le satisface demasiado, no deja de fracasar en sus relaciones sexoafectivas; mientras que el segundo, Michel, es un científico que creará una nueva raza humana y al que no interesa nada ningún tipo de relación sexual, pero tampoco personal.

Para analizar la novela, la estructura que sigue el presente trabajo es la siguiente: en primer lugar, nos ocuparemos de lo que Houellebecq ha llamado «ampliación del campo de batalla», tema fundamental en la obra de este autor y en el desarrollo de sus protagonistas - todos hombres, por lo que la primera sección servirá como una lectura de su obra en general a través del feminismoy que alude a la extensión de la lógica económica a la sexualidad, convirtiéndose esta en una especie de mercado donde hay ganadores y perdedores igual que ricos y pobres; en la segunda sección, nos ocuparemos de los dos protagonistas de la novela para explicar, con ellos, los rasgos de la masculinidad en crisis, por lo que será la sección más larga; la tercera y última parte la dedicaremos a las inseguridades - y las reacciones- de los hombres en Houellebecq, lo que nos hará comprender en qué peculiar sentido es provocador, un rasgo que identifican todos sus críticos. Una última nota: el presente artículo no se reducirá a mostrar la concepción houellebecquiana de la masculinidad, la cual, por otra parte, no está del todo clara, sino que lo que sigue pretende discutir el diagnóstico que hace el novelista francés ${ }^{1}$, señalando causas y consecuencias del mismo

\footnotetext{
1 Ha de advertirse desde el principio que la atribución que se hace a Houellebecq, a veces, de las tesis aparecidas en sus libros tiene que ser matizada por el hecho de que su obra está constituida mayormente por novelas y, por tanto, el narrador no solo no tiene por qué coincidir con el autor, sino que ha de separarse lo diegético y lo extralite-
} 
más allá de su propia obra; no nos reduciremos aquí, por tanto, a un estudio literario de la novela, sino más bien la confrontaremos con la tradición feminista y sus avances teóricos, sobre todo en lo que tiene que ver con la masculinidad.

\section{La obra de Michel HouellebecQ: la liberación Del MERCADO SEXUAL}

Me dirijo a todo aquel que nunca haya sido amado,
Que nunca supo gustar;
Me dirijo a los ausentes del sexo liberado,
Y del placer corriente.

No temáis, amigos, vuestra pérdida es mínima:

El amor no existe en ninguna parte.

Solo es una broma cruel de la que vosotros sois víctimas,

Una jugada de experto.

(Houellebecq 2012: 165)

La identidad masculina en la obra de Houellebecq está en crisis por una pérdida fundamental, o más bien, un desplazamiento: el del amor —en términos tradicionales - a la liberación de la sexualidad, en la que el autor, como muchos otros reaccionarios - paradigmáticamente, Daniel Bell—, observa la conversión de las relaciones sociales en un ámbito más del mercado; o sea, el desplazamiento del amor al mercado. En esto, sin embargo, Houellebecq —como Bell y los posmodernos conservadores $-^{2}$, coincide, con algunos matices como veremos enseguida, con el análisis de las relaciones

rario. Por ello, se ha intentado precisar casi siempre que es el narrador quien habla. No obstante, puede criticarse también que la ambigüedad de la novela permite a Houellebecq no responsabilizarse directamente de sus opiniones, a pesar de que recorran toda su obra novelística. La ambigüedad es, de hecho, un rasgo fundamental en Houellebecq, como puede verse en la tercera sección de este artículo, y, por tanto, no podemos pasarla por alto aludiendo a una cuestión narrativa que, en su obra, seguramente sea muy discutible. En todo caso, este artículo no puede ocuparse de la similitud entre la obra narrativa y la obra ensayística o las opiniones del autor, pero nos inclinamos a pensar que hay más similitudes que diferencias. Para ello, véase Houellebecq, M. Interventions 2020, París: Flammarion, 2020, donde se recogen sus artículos completos.

2 Véase Jameson, F. (2016) Teoría de la postmodernidad, Madrid: Trotta, págs. 85-96. 
sexoafectivas que llevan a cabo filósofos y sociólogos feministas, especialmente Eva Illouz.

Antes de entrar en ello, veamos cómo Houellebecq da cuenta, en Las Partículas, de esta transformación, lo que podemos resumir echando un vistazo a la estructura de la novela. El libro consta de tres partes y un prólogo. El prólogo ya nos presenta una de las consecuencias que Houellebecq extrae del mundo postsesentayochista, a saber, el individualismo extremo: «los hombres de su generación se pasaron además la vida en medio de la soledad y la amargura», lo que se expresa, claro, en lo romántico: «por lo general estuvo solo» (2001: 7). Este prólogo está escrito por un posthumano, la especie que Michel creará al término del libro, por lo que da cuenta de un mundo que ya se ha perdido; esa es la visión de Houellebecq sobre la modernidad en nuestro tiempo: está en su ocaso, es una modernidad tardía. Pero avancemos algo más. Las tres partes del libro son muy reveladoras en cuanto a este crepúsculo: la primera parte lleva por título "El reino perdido" — del todo significativo—y es donde encontramos la descripción de lo que verdaderamente se añora en la novela, lo que puede resumirse en el siguiente fragmento:

"Seres humanos que trabajaron toda su vida, y que trabajaron mucho, solo por amor y entrega; que dieron literalmente su vida a los demás con un espíritu de amor y de entrega; que sin embargo no lo consideraban un sacrificio; que en realidad no concebían otro modo de vida más que el de dar su vida a los demás con un espíritu de entrega y de amor. En la práctica, estos seres humanos casi siempre han sido mujeres" (2001: 92).

Aquí Houellebecq está hablando del amor tradicional, el cual, en sus novelas, fracasará siempre o estará simplificado y reducido a la generosidad de dar placer sexual al otro, como en Plataforma y en la segunda parte de Las Partículas. En la parte de la novela que nos ocupa, el fracaso deriva, como siempre en Houellebecq, de la pérdida: el amor-fusión —aunque el narrador sabe muy bien que esta fusión es falsa, de ahí que aluda al sacrificio en la cita anteriordesaparece metonímicamente con la pérdida, para Michel, de dos 
mujeres: la de la abuela, que muere, y que todavía estaba socializada en ese mundo presesentayochista que el narrador añora — es la que lo cría, además, cuando su madre lo abandona, exactamente igual que en el caso biográfico de Houellebecq-; y la de Annabelle, el amor de infancia y adolescencia de Michel, pérdida que tiene que ver con el modo en que aquella se inserta en el nuevo sistema sexoafectivo, quedando él relegado y rechazado por ser inepto para esa nueva disposición de las relaciones sociales, lo que veremos después.

La segunda parte está dedicada a ese nuevo mundo de "sexo liberado” y, por ello, todas sus páginas se centran más en Bruno, que es quien, de alguna manera, forma parte del sistema; tanto es así que Houellebecq, quien desdobla su alter ego en estos dos personajes, lo ve como la parte alienada de sí mismo: Michel piensa de su hermanastro que "podía aparecer como un individuo, pero desde otro punto de vista solo era el elemento pasivo del desarrollo de un movimiento histórico" (2001: 178). Esta parte lleva por nombre “Momentos extraños” y, en ella, Bruno comienza a tener experiencias sexuales satisfactorias en campamentos New Age, donde conoce a Christiane, quien representa ese sacrificio en el placer al que nos referíamos antes. Sin embargo, Houellebecq no da mucha tregua: si en estos momentos extraños presenta un mundo árido para quien no encaja en el mercado sexual, cuya única salida está en individuos como los de esas sectas, del todo apartados de la vida social tradicional, terminará mostrando la trampa a la que ese nuevo mundo conduce, a saber, la de que cuando el placer sexual no es posible, no se encuentran motivos para vivir - y esto será así siempre en función de la edad, elemento casi dinerario en el mercado sexual que Houellebecq concibe-. Así, esta segunda parte termina con otra pérdida, la de Christiane, quien, paralítica por un accidente, se suicida - representando la imposible duración del placer sexual en la modernidad tardía, acosado por el envejecimiento, que Houellebecq acelera con el recurso narrativo del accidente-, con la consiguiente vuelta de Bruno al psiquiátrico. En este punto, lo que se pierde es la vida sexual satisfactoria, segundo de los mitos que 
Houellebecq denuncia por ser precisamente eso, mitos del tiempo que les ha tocado vivir a sus personajes.

En la tercera parte, "Infinito emocional", asistimos a un reencuentro entre Michel y Annabelle, pero esta, tras no poder tener hijos, intenta suicidarse y queda en coma, muriendo más tarde igual que el propio Michel, quien también se suicida. La pérdida aquí es total: los únicos humanos que, en un mundo imposible para el amor, tuvieron una experiencia todavía semejante a este, sucumben ante el nuevo estado de cosas. Por eso Houellebecq crea una especie humana a partir de las investigaciones de Michel: ya la felicidad es algo que no tiene que ver con lo que concebimos como tal o, al menos, como dice en Serotonina, "ya nadie será feliz en Occidente [...] hoy debemos considerar la felicidad como un ensueño antiguo, pura y simplemente no se dan las condiciones históricas" (2019: 85).

Cabe preguntarse ahora por cuáles son los rasgos de ese mercado sexual liberado - $\mathrm{y}$, sobre todo, en qué afecta a la masculinidad-, dado que es lo que provoca la pérdida de lo que Houellebecq considera fundamental, la relación amorosa tradicional. El narrador de Las partículas lo resume de la siguiente manera:

"En un sistema monógamo, romántico y amoroso, solo pueden alcanzarse [el deseo y el placer] a través del ser amado, que en principio es único. En la sociedad liberal en la que vivían Bruno y Christiane, el modelo sexual propuesto por la cultura oficial (publicidad, revistas, organismos sociales y de salud pública) era el de la aventura. Dentro de un sistema así, el deseo y el placer aparecen como desenlace de un proceso de seducción, haciendo hincapié en la novedad, la pasión y la creatividad individual (cualidades por otra parte requeridas a los empleados en el marco de la vida profesional)" (2001: 247-248).

Veamos brevemente cómo se ha tratado esta cuestión desde la sociología. Eva Illouz sostiene que la publicidad se dio cuenta muy pronto de que tenía que ofrecer cierta “cura” para la fragilidad del matrimonio, por lo que "recomendaba el consumo de experiencias románticas intensas y de productos que estimularan la seducción, destinados a conservar la emoción inicial del romance” (Illouz 
2009: 70). Hoy podemos decir que el neoliberalismo ya no se preocupa por esto, sino por todo lo contrario: “desde los principios del capitalismo, las políticas del amor se formulan, cada vez más, como una política de la ruptura [...]; el acto de romper, "ya es oficial», siempre es público y formal. En el sistema de mercado ese acto se convierte en la forma más notoria de la renovación del sujeto como producto” (Fernández Porta 2012: 21). Dice Houellebecq en la novela que nos ocupa: "la liberación sexual provocó la destrucción de esas comunidades intermedias [pareja, familia], las últimas que separaban al individuo del mercado" (2001: 116). Ya no importa, o no importa solo ofrecerle al matrimonio la experiencia romántica intensa que le devuelva la pasión de la novedad, sino que el mercado ha de preocuparse también por esos que, valga la redundancia y como suele decirse frívolamente, "vuelven a estar en el mercado". Para ello, la publicidad no solo dispone el modo en que tienen que darse las experiencias románticas, sino que organiza las condiciones previas de las mismas: el soltero o la soltera tendrá que prepararse para el proceso de seducción que marca la publicidad y otros dispositivos ideológicos como paso necesario del surgimiento $-\mathrm{y}$ ha de creerse que es surgimiento espontáneo- del amor. No es solo que haya "actos de consumo previos a la cita (como la compra de ropa y artículos de belleza), al igual que realizados durante la cita” (Illouz 2009: 109), es decir, que el proceso de seducción tenga aparejado el consumo, casi confundiéndose con él; sino también que "esta «filosofía del sentido que fluye» alcanza un nuevo nivel de éxtasis, a saber: el éxtasis infinito del mercado" (Groys, citado en Fernández Porta 2012: 42). La circulación de amantes que impone la estrategia de la seducción —-seducir se enmarca dentro de la excepción y la novedad del affaire - podemos asimilarla a la circulación del capital, cuyo movimiento no es más que la premisa de un proceso de maximización. Pero lo que más importa de este proceso es no solo que se cosifique al objeto de deseo — aunque en el caso de las mujeres, esto sea mucho más nocivo-, sino que también uno se ofrece como producto que puede ser seducido y, por tanto, consumido. La edad, por supuesto, también entra en juego en la calidad 
de ese producto, aunque Houellebecq lo mira desde la reacción al feminismo, como dice en La posibilidad de una isla: "en cuanto quisieran acercarse al cuerpo de los jóvenes, serían perseguidos, rechazados, condenados al ridículo, al oprobio; y en nuestros días, cada vez con más frecuencia, a la cárcel [...] el destino de los viejos consistía en trabajar y sufrir" (2005: 356).

Aún dirá más Houellebecq en Ampliación del campo de batalla: "La sexualidad es un sistema de jerarquía social” (2016: 105). Y sí, pero con muchos matices. En Las partículas, Houellebecq expande este proceso a hombres y mujeres por igual, existiendo así guapos/ as y feos/as que triunfan o pierden en el mercado, pero esto es, en parte, falaz. Si la sexualidad es un sistema de jerarquía social, lo es en la medida en que se ha entrelazado con un sistema jerárquico mucho más fuerte, el patriarcado. Siguiendo este análisis, el que acumula más relaciones sexuales - acumulando experiencias como se acumula capital- será el que esté en la cima de semejante sistema; ahora bien, en esta maximización de las relaciones, cuyo eje es el número de veces que se vive la aventura amorosa, los hombres ejercen, dice Illouz, una dominación emocional: "la sexualidad acumulativa proporciona a los varones la ventaja estructural de retener sus emociones y de ser más renuentes que las mujeres a comprometerse [...], pues cuentan con una mayor variedad y cantidad de candidatas para elegir (en términos de lapso temporal ${ }^{3} \mathrm{y}$ de características demográficas" (2012: 140). Esto es expresado por una de las mujeres entrevistadas por la profesora Mari Luz Esteban,

\footnotetext{
3 Recuerda Illouz que la mujer se siente apresurada para encontrar pareja por los procesos biológicos del envejecimiento, que le afectan mucho más en términos patriarcales. Aquí Houellebecq yerra al tratar la vejez universalmente; aunque quizá no lo hace tanto como se cree, ya que reconoce que "el culto al cuerpo que habían contribuido tanto a establecer, las llevaba [a las mujeres], a medida que se marchitaban, a experimentar una repugnancia cada vez más viva hacia sí mismas” (2001: 107). Esta cuestión se ha evidenciado recientemente con las declaraciones de un escritor que pasa por polémico y que, sin embargo, con sus palabras nos ofrece una prueba más de la dominación masculina; Yann Moix, el escritor en cuestión, dijo que "era «incapaz de amar a una mujer de 50 años» porque las encuentra «demasiado viejas»”. Véase https://www.efe. com/efe/espana/cultura/el-escritor-yann-moix-pone-de-nuevo-cara-a-la-polemica-enfrancia/10005-4053124 (Consultado el 20 de enero de 2020).
} 
cuando dice que "con el tiempo he aprendido a comportarme como los hombres, en el sentido de no importarme dejar tirado a alguno. Antes [...] si tenía que dejar a uno, le acompañaba en el duelo. [...] Ellos son más «oye, ya te veré el año que viene» y adiós muy buenas” (2009: 31). También lo dice Ana de Miguel: los hombres resultan dominantes mientras que las mujeres "experimentan una continua decepción en sus relaciones y una falta de reciprocidad entre lo que aportan y lo que reciben. En las palabras de la marxista nórdica Jonasdóttir, experimentan la explotación de su capacidad de amar” (2017: 92).

Esta perspectiva no está en Houellebecq, porque sus protagonistas femeninas son siempre las treguas (sexuales) que el sistema ofrece, casi por caridad y siempre brevemente, a los protagonistashombres: eso son Christiane y Annabelle en esta novela. Asimismo, las posibilidades más allá de Occidente no escapan del mundo como supermercado, otro de los títulos houellebecquianos, y se expresa sobre todo en el turismo sexual: "van de compras no solo en busca de bienes de consumo, sino también de cuerpos” (Kimmel 2008: 24); lo que evidencia que la tregua en que consiste Plataforma — novela en que el amor se desarrolla en el marco del turismo sexual- no solo está transida de mercantilización, sino también de profundo poder patriarcal. Es más, Houellebecq no puede dar cuenta de esta realidad en la medida en que todas las mujeres que aparecen en sus novelas están siempre cosificadas y sexualizadas: "una descripción visual pasa inmediatamente a una apropiación física y erótica” (Morrey 2009: 150).

Ahora bien, lo más importante de la ausencia de este punto de vista con perspectiva de género es que no da cuenta de que la sexualidad se ha convertido en el ámbito esencial donde se juega el poder en nuestra época — como sí lo hicieran los filósofos franceses que Houellebecq critica- y que expresa Illouz: la sexualidad se convierte en el ámbito donde se manifiestan "los tres aspectos de la masculinidad como estatus, o sea, la autoridad, la autonomía y la solidaridad” (2012: 103). Esto ya lo había dicho Bourdieu: "el acto sexual en sí mismo está pensado en función del principio de 
primacía masculina” (2018: 31). Sin embargo, en Las partículas y en toda la obra de su autor, los protagonistas masculinos siempre fracasan $y$, cuando intentan imponerse, no causan miedo, sino risa y desprecio. Houellebecq da cuenta, en fin, de la experiencia masculina en esta nueva construcción de la experiencia sexoafectiva, por lo que ahora, en la segunda y tercera sección, nos centraremos en lo que verdaderamente nos interesa: cómo las categorías tradicionales de la masculinidad sufren y no se ajustan a este mercado sexual contemporáneo. En definitiva, tenemos que preguntarnos ahora cómo la obra de Houellebecq da cuenta de la puesta en jaque de una identidad, la masculina.

\section{El hombre mUtilado EN EL ALTER EGO ESCINDIDO: BRUNO Y MiCHEL}

¿Volveré a la discoteca? Me parece poco probable; ¿Para qué nuevos fracasos?

Prefiero mear en la arena

Y sacudir mi pequeña cola

Al viento fresco de Túnez

(Houellebecq 2012: 290)

En la obra de Michel Houellebecq hay una tensión entre cierta pretensión de universalismo y la muestra impúdica de un particularismo masculino, aunque eso no impide leer lo que se presenta como universal a la luz de lo particular, como, por ejemplo, la muerte que le diagnostica a la novela en Ampliación: "la forma novelesca no está concebida para retratar la indiferencia, ni la nada; habría que inventar una articulación más anodina, más concisa, más taciturna" (2016: 49). Podría sostenerse la tesis de que este rechazo de la novela viene a cuenta de la destrucción de la identidad o, al menos, de su distorsión (Castro 2016), pero habría que añadir que, en el caso de Houellebecq, es especialmente la crisis de la identidad masculina lo que pone en jaque a la novela como género literario, ya que el hombre tradicional no puede narrarse, sino tal vez solo lamentar su pérdida. De esa destrucción nos ocuparemos en esta 
sección, centrándonos en los personajes de Michel y Bruno. Para ello, dividiremos la sección en dos partes, una por cada personaje; pero, antes, nos detendremos en explicar quién es el "hombre mutilado" que ha descrito Elisabeth Badinter.

R. W. Connell ha dicho que "la masculinidad, así como la femineidad, siempre está asociada a contradicciones internas y rupturas históricas" (1997: 8). Pero Badinter da cuenta de una novedad en la literatura de la segunda mitad del siglo XX escrita por hombres, a saber, que vuelcan todos sus sentimientos respecto a la masculinidad: "la rabia, la angustia, el miedo a las mujeres, la impotencia, la pérdida de referencias, el odio a sí mismos y a los demás, etc. Hay una característica común a todos esos textos: el hombre llora” (1993: 53). Houellebecq, quien todavía en 1993 no había publicado nada, se inserta en esta tradición, bastante amplia, por cierto, como da cuenta la lista de novelas que Badinter nos ofrece (1993: 225-229). Badinter resume este hombre que llora en el concepto de "hombre mutilado", del que daremos cuenta brevemente. Badinter lo define como lo que sigue:

"el hombre-blando [...] es el que renuncia voluntariamente a los privilegios masculinos, el que abdica del poder, de la preeminencia del macho que le concede tradicionalmente el orden patriarcal [...] a menudo es la consorte feminista la que le impone a su compañero ese comportamiento que le es profundamente ajeno. El hombre se ve afectado en su masculinidad, su identidad bascula y, frecuentemente, la pareja se disuelve" (1993: 158).

Badinter entiende al hombre mutilado como aquel que ha sido obligado a adoptar otra identidad en la que no sabe desenvolverse, en tanto ha sido socializado en los términos de la masculinidad tradicional. Esto ya tiene efectos políticos: "la queja principal del ala blanca es que la América moderna ha castrado al hombre blanco" (Kimmel 2019: 377). Asimismo, Houellebecq se ha referido alguna vez al silencio de los hombres, quienes ya no pueden expresar su masculinidad; esa mutilación del hombre la expresa mejor una de sus personajes: “en pocos años [las feministas] conseguían trans- 
formar a los tíos que tenían al lado en neuróticos impotentes y gruñones. Y en ese momento, era matemático, empezaban a tener nostalgia de la virilidad. Al final plantaban a sus hombres para que las follara un macho latino de lo más ridículo" (2001: 147). El hombre, por tanto, está mutilado porque no puede desarrollar su masculinidad de forma tradicional, y la que intenta desarrollar no le sirve para alcanzar relaciones sexoafe ctivas satisfactorias. Lo ha dicho también Michael Kimmel analizando la reacción masculinista: "no saben si prefieren ser otra vez patriarcas o convertirse en hombres liberados" (2019: 168). En esta encrucijada están, asimismo, los personajes de Houellebecq, especialmente Bruno, quien opta por fingir una identidad de izquierda y feminista porque cree que así tendrá más posibilidades de acceder al sexo ${ }^{4}$ : "tenía que conservar mi postura de «izquierda humanista», era mi única oportunidad, tenía la íntima certeza” (2001: 197). La propia sexualidad es, de hecho, lo que Badinter identifica como una carga para el hombre mutilado: "hay que aprender a disociar sexualidad y sentimiento de virilidad para romper la identificación entre performance sexual y masculinidad, la cual se basa en algo más que en un pene en erección" (Badinter 1993: 156). Ahora bien, Houellebecq no ha roto este lazo, y esto se expresa de modo evidente en Las partículas, especialmente en el personaje de Bruno, del que nos ocuparemos a continuación.

Como no podemos ocuparnos del personaje en general, por cuestiones de espacio y de análisis, en tanto nos interesa contraponer a Houellebecq con los Men's Studies, elegiremos algunos fragmentos de la novela como sinécdoques del personaje. El primer momento destacable de Bruno en la novela tiene lugar en la primera parte, después de que se le haya descrito como un chico obeso y sometido al acoso y las humillaciones por parte de sus compañeros.

\footnotetext{
4 Muy interesante a este respecto ha sido la contribución de Antonio J. Rodríguez, quien ha sostenido que la nueva masculinidad ha sustituido aquello de lo que ha tenido, por fuerza, que desprenderse con otros rasgos masculinizantes, como la asistencia obsesiva al gimnasio (Rodríguez 2020: 25). El propio Rodríguez menciona que Houellebecq, con su decadencia física, representa completamente lo contrario (2020: 92).
} 
Bruno, intentando tener una experiencia — no se aclara si amorosa o sencillamente sexual, en fin, erótica- deja caer su mano en el muslo de una compañera de clase con quien había acudido al cine, a lo que ella responde apartándole la mano, lo que significa un trauma para el personaje: "tras este primer fracaso (porque desde el momento en que ella le apartó la mano él no se atrevió a volver a dirigirle la palabra) todo fue mucho más difícil” (2001: 55). Pero es que además el personaje de Bruno identifica este primer fracaso como la causa de su general fracaso amoroso y sexual: "si todo había caído en un vacío desolador, era por culpa de un detalle mínimo y grotesco [...] la culpa de todo la había tenido la minifalda de Caroline Yessayan” (2001: 55) piensa, por Bruno, el narrador, después de haberse preguntado por qué no le tocó un brazo en lugar de la pierna. Inmediatamente, Houellebecq establece una asociación entre este hecho y la liberación sexual, pero centrémonos en qué le ocurre a la identidad masculina aquí. Aunque Bruno se siente humillado por el rechazo de la chica, lo que en seguida trataremos, echa la culpa a la minifalda porque esta hace visible la posibilidad del sexo, lo que no significa que sea así para él. Lo dice el propio Houellebecq más adelante: "Bruno se masturbaba tres veces al día. Las vulvas de las chicas eran accesibles, a veces estaban a menos de un metro; pero Bruno comprendía muy bien que estaban cerradas para él: los demás chicos estaban más bronceados y eran más altos, más fuertes” (2001: 62). Lo que Bruno experimenta es la crítica que Houellebecq le hace al sesentayochismo: dicho burdamente, promete sexo para todos y, sin embargo, semejante promesa sucumbe a la mercantilización de la experiencia erótica que el feminismo ha asumido -o ha sucumbido en ella- como propia ${ }^{5}$. Bruno culpabiliza al sistema que le ha hecho actuar — un asunto delicado sobre el que volveremos, pues evade la responsabilidad de una situación de acoso como es

El primer capítulo de Ampliación del campo de batalla, su primera novela, es una prueba fehaciente de esta tesis; de ahí que pueda tomarse como una metonimia del resto de su obra (Morrey 2009: 12). 
manosear a una mujer- de manera superficialmente sexual y no de manera erótica.

Aquí está uno de los factores claves por los que la identidad masculina está en crisis, lo que Kimmel ha llamado "derecho agraviado, [que] consiste en sentir que aquellas ventajas sobre las que creíamos tener derecho nos han sido arrebatadas por fuerzas invisibles mucho más grandes y poderosas” (2019: 49). La situación de victimismo en que Houellebecq sitúa a su personaje también depende de esto, puesto que en el derecho agraviado reside "cierta clase de resentimiento cargado de razón” (Kimmel 2019: 48). La identidad masculina ve en el fracaso sexual el entorpecimiento de su propio desarrollo, y se declara víctima de un sistema que lo expulsa de las experiencias sexoafectivas; lo dice mejor Kimmel: "consiste en haberse apropiado de una cantinela — a menudo «femenina»de victimismo crónico y, acto seguido, masculinizarla con éxito. De hecho - tal como aseguran-, ¡lo que está en peligro permanente es tu misma hombría!” (2019: 77). Bruno, por tanto, deja de ser hombre en la medida en que uno de sus derechos ha sido arrebatado, el derecho al sexo, lo que no solo sería consustancial a la liberación sexual de los sesenta, sino a la emancipación de la mujer en las últimas décadas, con lo que puede decirse algo que es evidente: la masculinidad se ha construido tradicionalmente en virtud del poder masculino sobre el sexo femenino; de hecho, como señala Bourdieu, la relación sexual heteronormativa hace pasar "el deseo femenino como deseo de la dominación masculina, como subordinación erotizada, o incluso, en su límite, reconocimiento erotizado de la dominación” (2018: 35). Houellebecq, sin embargo, solo apunta a la pérdida del amor tradicional sin realizar crítica alguna del mismo, y la única salida que concibe a esta crisis de la masculinidad es la de la construcción de una sexualidad que permita y acepte costumbres como el voyerismo. Según la tesis que puede desprenderse de la novela, esta salida daría pie a la facilitación de las relaciones sexuales, sin que se produzcan estigmas sobre quienes no se ajustan al ideal de belleza, lo que se ambienta en sectas New Age y que el narrador llama "una sexualidad socialdemócrata" (2001: 222). Esta 
tregua ocupa buena parte de las páginas de la segunda parte de la novela, donde Bruno tiene experiencias sexuales satisfactorias, lo que le hace concebir la felicidad, pero, como dijimos, se termina con la pérdida de la mujer que sacrificaba su placer por el de él (y viceversa, puesto que Bruno se resigna a sus escasas capacidades sexuales). La pérdida de esta tregua, que había dejado entrever una felicidad posible, contribuye a la destrucción de la identidad masculina: es la pérdida misma de la sexualidad.

Ahora bien, hemos de atender a lo que antes solo dejábamos apuntado, el hecho de que Houellebecq haga pasar situaciones de acoso por situaciones en que la relación entre víctima y acosador se invierte. Lo anterior resulta obvio en otra de las vivencias de Bruno en Las partículas, a saber, los viajes en tren en los que se masturba delante de chicas "a menos de dos metros" (2001: 64), una de las situaciones de violencia simbólica más comunes en nuestro tiempo, y sin embargo, en ella Bruno pasa por un fracasado sexual que tiene que contentarse y conformarse con la masturbación. Houellebecq, un par de páginas más tarde, diluye, finalmente, el acoso en la humillación masculina: “[Bruno] terminó por enseñarle la polla a una vendedora de supermercado; afortunadamente, ella se echó a reír a carcajadas y no lo denunció” (2001: 66). He aquí el mayor miedo del hombre: que se rían de él. Pero no es un miedo por excesivo sentido del ridículo, sino porque, como dice Kimmel, “[la] vergüenza, [la] inadaptación, [y la] vulnerabilidad: todas [son] amenazas para el ego" (2019: 127). En la risa, se pone en jaque la identidad masculina, y Houellebecq victimiza al hombre blanco tardomoderno relacionando su sexualidad, que se expresa en términos de poder, con la destrucción de su identidad en la vergüenza ${ }^{6}$. Puede tildarse a Houellebecq de machista en tanto que convierte en víctima al acosador, pero su descripción de Bruno nos ofrece la imagen exacta de la masculinidad en crisis en relación con la sexualidad.

\footnotetext{
6 Recuérdese que esto es propio de la masculinidad tradicional o hegemónica: "la virilidad, incluso en su aspecto ético, es decir, en cuanto que esencia del vir, virtus, pundonor (nif), principio de la conservación y del aumento del honor, sigue siendo indisociable, por lo menos tácitamente, de la virilidad física” (Bourdieu 2018, 24).
} 
Para todo lo anterior, el hombre mutilado responde de dos maneras: violenta o resignadamente. Por ahora, dejaremos la violencia, a la que le dedicaremos la tercera sección, para centrarnos en esa segunda respuesta del hombre al nuevo orden que le ha tocado vivir. Esa resignación también está muy presente en Houellebecq $y$, concretamente, en el personaje de Michel. No es casualidad, me temo, que el protagonista esté desdoblado en Las partículas: si bien las novelas de Houellebecq suelen tener un solo protagonista, el hombre blanco y heterosexual de mediana edad, aquí nos encontramos con dos que representan, a mi juicio, esa misma escisión del hombre de la que habla Badinter. Si la mutilación del hombre ha dado lugar al rechazo del hombre duro y la desorientación del hombre blando, aquí tenemos a un hombre duro (Bruno) que no ha podido desarrollar, debido a los acosos y a los rasgos físicos que lo dejan fuera del sistema sexual, su masculinidad tradicional y que, aun así, lo sigue intentando a través de situaciones de violencia simbólica - y reparadora, como veremos en la sección tercera-; pero, de igual modo, encontramos a un hombre blando (Michel) que se ha resignado a su falta de deseo, de lo que Houellebecq culpa, como ya se sabe, a la época que le ha tocado vivir. De hecho, esta oposición entre duro y blando sirve para muchas de las características de los personajes: mientras que Michel se muestra silencioso, indiferente al sexo e incluso, en un momento de la novela, a la infidelidad, Bruno es histriónico y vehemente. Las diferencias entre ambos se observan muy bien cuando asisten a los últimos momentos de vida de su madre, donde Bruno le insulta y desprecia mientras que Michel actúa con una mezcla de pena y algo de curiosidad. Con Bruno y Michel tenemos dos hombres mutilados, sí, pero también tenemos la escisión del propio hombre contemporáneo, sobre todo en lo que a sus reacciones se refiere; y Houellebecq se mira en Michel analizando a Bruno, como antes se dijo. Veamos ahora, por tanto, el personaje de Michel.

Michel es, no solo por el nombre, el que seguramente más se corresponde con el autor, funcionando, igual que en sus otras novelas, a modo de alter ego — aunque ya dijimos que este estaba 
escindido-. Igual que Houellebecq, Michel se cría con su abuela después de que su madre le abandonara, y he aquí ya el primer rasgo clave en la construcción, o destrucción, de la identidad masculina. Badinter sostiene, a través del psicoanálisis, que "el amor materno es excesivamente fuerte, excesivamente gratificante [...] [y] [si] ese amor total no ha sido recíproco, el crío pasará el resto de su vida buscando dolorosamente" (1993: 67). Esta es la situación tanto de Bruno como de Michel, pero en Michel parece que este problema es mucho más grave; como el narrador sostiene para explicar que Michel no pueda besar a Annabelle, "la privación del contacto con la madre durante la infancia produce perturbaciones muy graves del comportamiento sexual en la rata macho, provocando en particular la inhibición del cortejo. Aunque su vida hubiera dependido de ello (y en gran medida dependía), Michel habría sido incapaz de besar a Annabelle" (2001: 61). El Edipo mal resuelto de Michel se expresa en la nulidad de su deseo: "la polla le servía para mear, y eso era todo" (2001: 22), exactamente para lo que sirve, nótese en el epígrafe de esta sección, cuando se ha fracasado en la seducción. La búsqueda de ese amor materno ausente, en toda la obra de Houellebecq, y en Michel en particular, se resuelve en una indiferencia ante la pérdida que se debe a la banalización de los vínculos afectivos; así, de Michel, tras perder a su abuela y al amor de su infancia, lo único que sabemos es lo que sigue: "su cara no reflejaba nada parecido a la pena ni a ningún otro sentimiento humano. La invadía un miserable terror animal” (2001: 94). En toda la obra de Houellebecq encontramos la misma resignación ante la pérdida de seres queridos o la repentina soledad; Michel, en su caso, se repliega a una vida rutinaria y profesional donde la búsqueda del placer, pero también cualquier estímulo, está fuera de juego. Para Houellebecq, por tanto, la ausencia de amor materno entorpece el desarrollo del yo, expulsándolo de la normalidad de las relaciones sociales y recluyéndolo a no saber desenvolverse emocionalmente - lo que Badinter, por cierto, comparte, aunque ella avanzará más y propondrá un "hombre reconciliado" que aúne lo femenino y lo masculino-. 
Ahora bien, aunque el lector se sorprenda — si es cierta la tesis houellebecquiana de la búsqueda del placer es el principio narcisista de nuestra época (2001: 161) — del celibato que mantiene Michel, esta actitud es muy común en las crisis de la masculinidad. Dice Kimmel que "las estrategias a las que se ha recurrido para solventar las numerosas crisis de la masculinidad [...] siguen siendo las mismas: [...] el autocontrol, la huida y la exclusión" (2008: 22). El autocontrol y la exclusión se dan, respectivamente, a través del culto al cuerpo y la reacción política contra las mujeres. No parece que ninguna de estas sea la estrategia de Michel, ni siquiera del propio Houellebecq $^{7}$. Sí hay, no obstante, una estrategia de huida. Huye, primero, de la masculinidad tradicional: "Michel comprendió rápidamente que le interesaba marcar distancias con aquellos jóvenes brutos; por el contrario, no había mucho que temer de las chicas, que eran seres más dulces" (2001: 165), pero, sobre todo, huye de la sexualidad, que es el ámbito donde, como dijimos, se juega la identidad masculina. La huida paradigmática, según Kimmel, es partir al campo desde la ciudad —recuérdese al protagonista de El mapa y el territorio-; aquí estamos en una huida semejante, puesto que se huye de la sociedad con un aislamiento atroz, desde las relaciones íntimas hasta las más banales. El propio Kimmel ha mostrado que esto es común en la crisis de masculinidad de nuestro tiempo cuando dice que "hace ya mucho tiempo que el hombre ha pasado a ser «el sexo suicida»" (2019: 320). Kimmel identifica las causas de los suicidios en la desvinculación y aislamiento del hombre, lo que se expresa, por otra parte, en depresiones que aguantan lo que su masculinidad no deja expresar emocionalmente, un rasgo tradicional de la misma (Kimmel 2019: 323). E incluso lo dijo Benjamin hace décadas: "la impotencia masculina: figura clave de la soledad. Bajo su signo se

\footnotetext{
Esta frase admite muchos matices y es muy discutible. En primer lugar, el personaje de Bruno, para poder acceder a las relaciones sexuales, lo primero que hace es ir al gimnasio y cuidar su cuerpo. En segundo lugar, Houellebecq parece añorar, en toda su obra, un orden romántico en que las mujeres estaban excluidas, pero esto no puede asegurarse del todo, debido a que estamos ante novelas y no ante obras teóricas.
} 
consuma la detención de las fuerzas productivas. Un abismo separa al hombre de sus semejantes" (2008: 287).

Pero la huida de Michel, a pesar de que se expresa de esta manera, no renuncia al regreso, o al buen desarrollo de su identidad: "Él solo quería amar; al menos no pedía nada. Nada concreto. La vida, pensaba Michel, tenía que ser algo sencillo; algo que pudiera vivirse como un conjunto de pequeños ritos, indefinidamente repetidos. Ritos al fin y al cabo estúpidos, pero en los que, en el fondo, se pudiera creer” (2001: 120). La crisis de identidad que sufre Michel es la de no poder ajustarse al nuevo sistema sexoafectivo, a causa del Edipo mal resuelto y provocado — esto es esencial- por un orden social de liberación sexual y vínculos efímeros - mercantiles-. Houellebecq diría, seguramente, que esta crisis es propia de todo hombre ( $\mathrm{y}$ de casi todo ser humano independientemente de su género aunque, como ya hemos mostrado, su diagnóstico es particularmente masculino). De ahí que Houellebecq solamente contemple dos salidas: el suicidio, tras mucha resignación, o la eugenesia. Esta segunda será la que el propio Michel ponga en práctica: "el mayor mérito de [Michel] Djerzinski [es] [...] haber sido capaz de restaurar, gracias a interpretaciones sin duda un poco aventuradas de los postulados de la mecánica cuántica, las condiciones de posibilidad del amor” (2001: 308). Sobre lo que significa el discurso científico para la masculinidad en Houellebecq nos ocuparemos después.

Estos dos personajes, que son un alter ego escindido, igual que el hombre de la modernidad tardía que diagnostica Badinter, se mezclan en todos los demás protagonistas de la obra de Houellebecq, dando cuenta de sus fracasos sexuales, su falta incipiente de deseo — con frustración sexual- y su aislamiento debido a todo ello. Como dice el protagonista de Sumisión: "mi polla era en el fondo el único de mis órganos que nunca se había manifestado a través del dolor sino del placer [...] Mi interés por la vida intelectual había disminuido mucho; mi existencia social no era mucho más satisfactoria” (2015: 95). Pero en Houellebecq no todo es 
resignación, depresión y suicidio. En ocasiones, también aparece la violencia.

\section{LA INSEGURIDAD MASCULINA Y SUS REACCIONES}

Si también, y a la vez, necesitamos sentirnos culpables, Sentirnos humillados e infelices por no ser más de lo que somos

Si realmente necesitamos todo eso para sentirnos hombres, ¿Qué le vamos a hacer?

Es tiempo de aflojar la presa.

(Houellebecq 2012: 215)

En Las partículas elementales, encontramos algunos episodios sobre la inseguridad de la identidad masculina, sobre todo en relación con la sexualidad. Así, una de los personajes espeta: "la mayoría de los hombres prefieren la mamada [...]. La penetración les molesta, tienen problemas de erección” (2001: 140). Ese problema se muestra cuando Bruno se pone un preservativo, que le causa impotencia, a lo que este responde: "“Nunca he sabido acostumbrarme..." [y dice Houellebecq:] Cumplida esta pequeña ceremonia, habiendo salvado el honor de su virilidad, podían volver a acostarse, acurrucarse contra el cuerpo de su mujer, dormir en paz" (2001: 145). Pero todo ello, si bien aparece en la obra de Houellebecq y tiene importancia para sus personajes, no es una inseguridad tan importante como la que surge de la desorientación en las relaciones con mujeres. Lo que sufren los personajes de Houellebecq, y especialmente Bruno, es la inseguridad a la hora de cumplir con los ritos sociales que dan -o devuelven, según el derecho agraviado patriarcal en que se han socializado- el acceso al sexo. Es aquí donde surge la violencia, también en la novela que nos ocupa.

Detengámonos, de nuevo, en el personaje de Bruno en otro de los momentos de la novela. Bruno, en el campamento sexual donde conocerá a Christiane, despierta un día con una erección y, enseguida, el narrador dice: "la frustración sexual crea en el hombre una angustia que se manifiesta en una crispación violenta, localizada a nivel del estómago; el esperma parece subir hacia el bajo vientre y 
lanzar tentáculos hacia el pecho. El órgano mismo está dolorido [...] Según el último mito de Occidente, el sexo era para practicarlo; algo posible, algo que habia que hacer" (2001: 132, el énfasis es mío). En este mito está el derecho agraviado del que hablábamos en la segunda sección. Como vemos, no está claro qué entiende Houellebecq por la "crispación violenta" con la que reacciona el hombre. Parece tan solo interna, sin resolverse si esa violencia se expresa de algún modo. Eso se materializa en la violencia de la obra, que siempre es latente y nunca se desencadena o, cuando lo hace, se resuelve de una manera asumible para el lector, sea positiva o negativamente. En la obra de Houellebecq, la violencia solamente se roza, desde su primera novela, Ampliación del campo de batalla, en que uno de los personajes decide asesinar a la chica que lo ha rechazado, auspiciado por el protagonista típico houellebecquiano, que le dice que es su única solución (2016: 132), hasta la última, Serotonina, en la cual el protagonista pasa unos días con un rifle de francotirador apuntando a su exmujer, sin llegar a disparar. Houellebecq está jugando con la idea de la violencia que Kimmel identifica en los hombres blancos cabreados, a saber, que la violencia repara la humillación sufrida y, sobre todo, la identidad masculina (2019: 124-127). Una tesis semejante maneja Carlos Thiebaut: "una reacción violenta ante la propia conciencia opaca de la imposibilidad de la propia identidad" (Thiebaut 2010: 154). Houellebecq aquí es profundamente ambiguo - como ambigua es la diferencia entre narrador y autor al tratarse de novelas-y, por tanto, provocador hasta el extremo.

En Las partículas, ya hemos descrito algunas de las situaciones de acoso que provoca Bruno, pero la que más se ajusta a esta violencia latente es, precisamente, el episodio en que Bruno encuentra la solución a sus problemas, es decir, cuando conoce a Christiane, la mujer que le dará placer durante algún tiempo y con la que, literalmente, alcanza "la posibilidad práctica de la felicidad" (2001: 249). Este episodio ocurre en un jacuzzi, donde Bruno ve a Christiane teniendo sexo con otro hombre. En esa misma página, tal vez la más fundamental de la novela, Bruno ha dicho: "en resumen, que nunca ha habido comunismo sexual; solo un sistema de seducción 
ampliado" (2001: 138), lo que es el desmontaje que hasta hace un momento habíamos identificado como mito occidental: que el sexo era un derecho. Una vez que Bruno contempla la escena del jacuzzi, se quita la ropa “a toda prisa” y se mete en el mismo. “"Estoy en mi derecho... » pensó Bruno con rabia” (2001: 138). He aquí la reacción al derecho agraviado: el sexo es un derecho que, impulsivamente, se recuperará por la fuerza. $\mathrm{O}$ eso piensa el lector todavía en este punto, Houellebecq juega con la ambigüedad. Pero una vez que el otro hombre se va, la mujer se acerca a Bruno y le hace una felación: "todo el cuerpo de Bruno se estremeció de felicidad" (2001: 140). Houellebecq juega, por tanto, con la provocación misma: si nos había preparado para asistir, por lo que se intuía, a una violación, puesto que la victimización de Bruno, tanto en la infancia como en su adultez, constituye toda la construcción del personaje, en el momento álgido afloja la tensión concediendo una tregua que durará hasta el accidente de Christiane — del mismo modo, en Ampliación, el coprotagonista de la novela no termina asesinando a la chica, sino que se masturba viéndola tener sexo- - La violencia aquí es reparadora en la medida en que una decisión tomada desde el poder masculino ha llevado a la solución de la frustración sexual; en este punto, encontramos la ambigüedad de Houellebecq: “a juzgar por lo que sienten los hombres, la masculinidad tal vez no equivaldría a la experiencia del poder, pero sí a la experiencia de merecer el poder por derecho" (Kimmel 2019: 278). No se puede concluir, por tanto, que sea la violencia lo que es reparador para los personajes de Houellebecq — tal vez porque, en general, no hay nada reparador en su obra, excepto la eugenesia-, pero esa ambigüedad puede hacer sentirse identificados a muchos hombres que, como el libro de Kimmel muestra, expresan violentamente las mismas quejas que Bruno - y el protagonista hombre houellebecquiano en generalesgrime sobre su situación, la cual consideran injusta.

Para terminar esta sección, cabe preguntarse en qué medida la obra de Houellebecq constituye lo que Kimmel llama una "Viagra política”, esto es, un conjunto de discursos que hacen reaccionar al hombre blanco heterosexual (2019: 80). Primero, Kimmel identifica 
la reacción en un hombre cuyas dosis de indignación provienen no solo de la sexualidad o la relación con las mujeres, sino también de la pérdida de trabajo por la desindustrialización occidental. Ahora bien, esta situación no es la del protagonista típico houellebecquiano; en Las partículas, tanto Bruno como Michel tienen el factor económico holgadamente resuelto, y lo único que les preocupa es la sexualidad. Esto no quita, sin embargo, que haya afinidades entre los “perdedores de la globalización", como se ha dado en llamar a aquellos, y los personajes de Houellebecq: ambos reaccionan ante lo que se ha llamado "políticas de identidad", es decir, la resaca del sesentayochismo. Es más, en Houellebecq estos personajes aparecen, solo que lateral y secundariamente. En Serotonina, por ejemplo, hay un conjunto de agricultores que protestan contra las reformas europeas, lo que podríamos tomar como que Houellebecq ha dado cuenta de dónde está su discurso, porque la segunda característica que Kimmel extrae de esas viagras políticas es que logra "crear una comunidad a partir de las frustraciones individuales de la gente” (2019: 83). De hecho, el estilo de Serotonina es mucho más autoconsciente, como si el autor hubiera querido plasmar todas sus obsesiones, y casi una imagen de sí mismo como autor, en la novela. Es cierto, por tanto, que Houellebecq es un provocador, pero no está tan claro que sus novelas constituyan esa viagra política que Kimmel identifica en los periodistas de extrema derecha. Esta es una cuestión muy problemática en tanto Houellebecq, como hemos visto, es un autor muy ambiguo, que permite identificar muchos rasgos de la masculinidad en crisis a la par que provoca hasta un punto asumible y a través de la ficción. Me inclino a pensar que sus novelas no constituyen una viagra política no porque las considere valiosas para identificar la crisis de la masculinidad, que también, sino porque, como dice al final de la novela que hasta aquí nos ha estado ocupando, la única salida "solo podía ser una solución de orden técnico” (2001:318), es decir, eugenésica. No hay salida política ni políticamente reaccionaria. Y esto lo dice justo después de sostener que las filosofías de Foucault, Lacan, Derrida y Deleuze habían hecho el ridículo, cediendo ya todo el paso a la ciencia, como 
si de Sokal se tratara. Pero no nos quedemos con lo superficial: lo que está diciendo Houellebecq aquí es que lo que han fracasado han sido las filosofías del deseo, es decir, aquellas que pretendían la emancipación por la deconstrucción de la sexualidad tradicional.

De todo ello deriva que Houellebecq adopte un discurso cientificista, lo que constituye, junto con las situaciones de cosificación de la mujer o de victimización del acosador, otro de los rasgos por los que la masculinidad tradicional intenta salvarse a sí misma. Como bien dice Morrey, "la apelación al discurso científico o evolucionista en la obra de Houellebecq tiende a naturalizar su presentación de la sexualidad humana" (2009: 151). Con esto, Houellebecq naturaliza la diferencia de género y los roles asociados a éstos. En Las partículas suele hablar y asociar características a "hombres y mujeres", e incluso llega a explicar el placer sexual, en un par de ocasiones, con un discurso biológico, a través de los corpúsculos de Krause. Es contradictorio, sin embargo, que Houellebecq aluda a los cambios culturales del sesenta y ocho como los causantes de un orden sexoafectivo que causa muchos males en los hombres, como hemos visto, y que a su vez explique el placer, y buena parte del comportamiento de género, en términos biológicos. Lo que importa, en fin, de este discurso cientificista es que no toma a la masculinidad como un género que es construido $-\mathrm{y}$ destruido, como el propio Houellebecq da cuenta - culturalmente, con lo que poder empezar a reconciliar al hombre mutilado que aparece en sus novelas.

\section{Conclusiones}

Las partículas elementales termina con la siguiente frase: "Este libro está dedicado al hombre" (2001: 320), justo después de habernos hablado un posthumano que nos informa de que ya quedan pocos humanos. Sin embargo, podemos tener la legítima duda de a qué hombre se refiere Houellebecq: ¿al universal o al particular? Este artículo cree que Houellebecq termina dedicando el libro al hombre cuya masculinidad tradicional, efectivamente, está muriendo. Houellebecq lo dice en Serotonina: "es así como muere una civili- 
zación, sin trastornos, sin peligros y sin dramas y con muy escasa carnicería, una civilización muere simplemente por hastío, por asco de sí misma” (2019: 130). Pero de nuevo confunde el universal con el particular: es el hombre quien, por cierto asco de sí mismo, no sabe cómo continuar siendo hombre.

Como hemos visto a lo largo de las secciones, la obra narrativa de Houellebecq mantiene la tesis implícita de que el nuevo orden romántico ha desatado una crisis de la masculinidad casi sin precedentes, en la que los hombres no saben desenvolverse y optan por el suicidio o las "soluciones técnicas" como la medicación o la eugenesia. Asimismo, el autor pretende extender este diagnóstico a ambos géneros, aunque han de tenerse en cuenta todas las matizaciones que se han hecho, en la primera sección, sobre la falsa imagen que las novelas de Houellebecq transmiten sobre la situación de las mujeres en la contemporaneidad. Lo más relevante, sin embargo, es el retrato que hace Las partículas elementales de la resquebrajada identidad masculina, que considera el sexo como un derecho, y su carencia como un derecho agraviado. Ante el desconcierto sobre cómo desarrollar la identidad sexual, los hombres optan por la apatía o por la violencia, con las que juega el autor para ofrecernos una provocación ambigua, siempre al borde de estallar, la cual es seguramente el rasgo más importante de la narrativa de Houellebecq y lo que le ha convertido en un autor muy polémico y discutido.

No obstante, la obra de Houellebecq nos sirve como diagnóstico de la crisis de una masculinidad que tiene que empezar a pensar en cómo solucionar los problemas identificados. La resignación houellebecquiana, por supuesto, no es una solución. Lo que hemos dado en llamar nuevas masculinidades es lo que nos apunta el camino a los hombres, como el que aquí escribe, pero esto ya es otra cuestión, de la cual Houellebecq no se da, o no se quiere dar, por enterado. 


\section{REFERENCIAS BIBLIOGRÁFICAS}

BADINTER, Elisabeth

1993 XY. La identidad masculina. Madrid: Alianza Editorial.

Benjamin, Walter

2008 "Parque central". En Obras. Libro I. Vol. 2. Madrid: Abada, $261-301$.

Bourdieu, Pierre

2018 La dominación masculina. Barcelona: Anagrama.

CASTRO, Ernesto

2016 “Get laid with Houellebecq!” En Un palo al agua. Ensayos de estética. Murcia: Micromegas, 101-116.

Connell, Raewyn

1997 "La organización social de la masculinidad" En Masculinidad/ es. Poder y crisis. Eds., Teresa Valdés y José Olavarría. Santiago: Isis, 31-48.

De Miguel, Ana

2017 Neoliberalismo sexual. El mito de la libre elección. Madrid: Cátedra.

Esteban, Mari Luz

2009 "Identidades de género, feminismo, sexualidad y amor: los cuerpos como agentes”. Política y Sociedad. 46, 1 y 2, 27-41.

Fernández Porta, Eloy

2012 Eros. La superproducción de los afectos. Barcelona: Anagrama.

HouellebecQ, Michel

2001 Las partículas elementales. Barcelona: Anagrama.

HouellebecQ, Michel

2012 Poesía. Barcelona: Anagrama.

HouellebecQ, Michel

2015 La posibilidad de una isla. Barcelona: Alfaguara.

HouellebecQ, Michel

2015 Sumisión. Barcelona: Anagrama.

HouellebecQ, Michel

2016 Ampliación del campo de batalla. Barcelona: Anagrama. 
HouellebecQ, Michel

2019 Serotonina. Barcelona: Anagrama.

ILLOUZ, Eva

2009 El consumo de la utopía romántica. El amor y las contradicciones culturales del capitalismo. Buenos Aires: Katz.

ILLOUZ, Eva

2012 Por qué duele el amor. Una explicación sociológica. Buenos Aires: Katz.

Kimmel, Michael

2019 Hombres (blancos) cabreados. La masculinidad al final de una era. Valencia: Barlin Libros.

KimmeL, Michael

2008 "Los estudios de la masculinidad: una introducción" En La masculinidad a debate. Eds., Àngels Carabí y Josep M. Armengol. Barcelona: Icaria, 15-31.

Morrey, Douglas

2009 "Sex and the Single Male: Houellebecq, Feminism and Hegemonic Masculinity”. Yale French Studies. 116/117,141-152.

Rodríguez, Antonio J.

2020 La nueva masculinidad de siempre. Capitalismo, deseo y falofobias. Barcelona: Anagrama.

Thiebaut, Carlos

2010 "Violencia de género y la hipótesis de la violencia anómica". En Historia y pensamiento en torno al género. VV.AA. Madrid: Dykinson,135-157.

Recepción: 25/11/2020

Aceptación: 29/03/2021 